\title{
Smart Phones, a Powerful Tool in the Chemistry Classroom
}

Antony J. Williams*

ChemSpider, Royal Society of Chemistry, U.S. Office, Wake Forest, NC 2758

*williamsa@rsc.org

Harry E. Pence

Department of Chemistry and Biochemistry, SUNY College at Oneonta, Oneonta, New

York 13820;

\begin{abstract}
Cell phones, especially "smartphones" (see note), are being widely used by students. It is misleading to call many of these devices phones, since they are actually a portable and powerful computer that can be valuable in the chemistry classroom. Currently, there are three major ways in which smartphones can be used for education. Smartphones include a web browser, which gives access to the wealth of material on the World Wide Web (WWW), inexpensive applications (commonly called apps) expand this usefulness even further, and two-dimensional barcode labels can be used to create "smart objects." Taken together, these capabilities are creating a world of mobile computing whose impact on society, including chemical education, may be even greater than the changes brought about by the personal computer.
\end{abstract}

\section{Keywords}

First-Year Undergraduate / General; graduate education/research; cheminformatics; laboratory instruction; computer-based learning; Internet/Web-based learning; StudentCentered Learning, smartphones.

\section{Feature}

None 


\section{Smart Phones, a Powerful Tool for the Chemistry Classroom}

Antony J. Williams*

ChemSpider, Royal Society of Chemistry, U.S. Office, Wake Forest, NC 27587;

*williamsa@rsc.org

Harry E. Pence

Department of Chemistry and Biochemistry, SUNY College at Oneonta, Oneonta, New

York 13820

\section{Introduction}

Cell phones are clearly ubiquitous in the hands of students (1), and smart phones, such as the iPhone, Blackberry, or Android, are becoming increasingly common. A recent survey shows that $85 \%$ of high school students have an iPod or similar MP3 player, some with internet accessibility, $70 \%$ have a laptop or netbook and 30\% have smart phones (2).

Such numbers continue to grow. For the younger generation the cell phone is much more than a phone. Many young people use the short message services (SMS), commonly called texting, rather than e-mail and cell phone cameras are replacing traditional cameras. Smart phones are not just radically changing the way people communicate; they are powerful computers that are small enough to always be carried in the pocket. The present generation of college students is adopting these devices and appears to be using them almost constantly (3). Smart phones are already used by a large number of students and are becoming increasingly popular. These devices have many valuable capabilities that have a tremendous potential for use in chemical education.

\section{Access to Chemistry Applications}

In a recent review one of us (AJW) outlined the new world of "Mobile Chemistry" and "Generation App", a generation of users who expect "an app for that" on their smart phone, whatever the brand (4). For chemistry students, developers are being responsive with the release of an increasing number of applications that can be downloaded at no charge or purchased for a tiny fraction of the cost of desktop software. Applications are already available for chemists to practice their chemistry skills, to access tables of chemistry-related data, to sketch small molecules and to rotate large biomolecules. While the included web browsers often suffice to search online databases, increasingly lightweight applications are being delivered for the smart phones.

Chemistry publishers provide smart phone access to science news stories and updated feeds of their latest publications, either the abstracts or the full text for immediate review or for saving locally to read later. Presently, the American Chemical Society iPhone app searches over 850,000+ scientific research articles and book chapters by author, keyword, title, abstract, digital object identifier or bibliographic citation. Podcasts are also available 
from scientific organizations, such as the Royal Society of Chemistry and the Nature Publishing Group $(5,6)$.

Smartphone apps can deliver facts and study guides while chemical calculator apps provide utilities to allow bench chemists to calculate molarities or the dilutions of stock solutions (7). Many chemical data tables associated with either the elements or chemical compounds are available (8). It is now even possible to draw chemical compounds on a smart phone (9). The visualization of biomolecules is possible, and three dimensional renderings of large molecules are available from the RCSB Protein Data Bank (10). Access to millions of compounds on web-based databases is already feasible. ChemMobi (11) provides access to over 30 million chemicals, searchable by chemical names or identifiers as well as retrieving information including the chemical structures, calculated properties and commercial availability from over 860 suppliers. ChemSpider (12), a very large online database that contains information for almost 25 million chemical compounds, has recently added browser-based access, optimized for mobile devices (13), and mobile browser access to other public domain databases is likely to expand in the near future.

In addition to specific applications for Chemistry, there are many smart phone apps that are generally useful in the classroom. These allow a teacher to use a smart phone to perform common tasks, such as link pictures of their students with class rosters, log observed data, capture notes from a whiteboard, scan documents, or do concept mapping (14).

\section{III.Augmented Reality Applications in the Chemistry Classroom}

Chemists are just beginning to explore how the combination of smart phones and augmented reality might be used in the classroom, but libraries, museums, and some companies are already using this capability (15). Augmented reality can be defined as the combination of digital information with images from the real world. There are two types of augmented reality commonly used on smartphones, markerless and markered (16). Markerless augmented reality adds digital information to the image on a cell phone camera based on the Global Positioning System (GPS) location; markered augmented reality uses a physical reference point, such as a two-dimensional barcode to connect a cell phone to information. Markered augmented reality is especially useful for chemists, since it provides an easy way to connect information directly to a physical object, like a scientific instrument, or to place a web link on a sheet of paper or a book.

A variety of different types of two-dimensional (2D) barcodes are available (see Figure 1), and there are free programs to convert a URL (Uniform Resource Locator) into a barcode and also to read the resulting barcode with a smartphone (17). This enables one to place a label on an object, i.e. an instrument, a bottle of chemicals, or even a sheet of paper, which allows the smart phone to access a web site related to the object. Barcodes have already been extended to support 
chemical structure encoding (18). Currently, quick response (QR) codes seem to be most popular, but this situation could change in the future with the expansion of usage of other forms of barcodes.

Hyperlinking is probably one of the most powerful features of web pages since clicking a hyperlink on a web page can immediately connect the reader to a new web page. A barcode on a physical object makes the object clickable to a smartphone, so that it is similarly linked to further information. This creates what is called a "smart object."

Barcode-labeled smart objects can be very useful in the chemistry laboratory. For example, the barcode on an instrument could connect the user to up-to-date operating instructions or even a video showing the correct use. Since the instructions would actually be a web page, they could be updated whenever necessary, instead of having multiple versions of the instructions or, and more likely, not being able to find the instructions when they were needed. A bottle of chemicals with a barcode could redirect the user to an MSDS sheet or other chemical and physical information. Even a simple page of laboratory instructions could now connect to a video showing how a procedure should be done.

This only begins to scratch the surface of the possible applications. Several companies are marketing systems that create barcodes for sample labeling that would hold a large amount of information and significantly decrease processing time (see, for example, reference 17). These companies argue that 2D barcodes can contain much more information than the traditional 1D format, and so improve safety, accuracy, and efficiency. Although these companies generally use proprietary formats and dedicated scanners, it is easy to envision how this technique could be inexpensively adapted to using a smartphone. 


\section{How Will the Smart Phone Change the Chemistry Classroom?}

Some professors would rather ban cell phones than use them for education, fearing that students would spend their class time texting or web browsing. Howard Rheingold writes that too often students are in a state of continuous partial attention, a term that he adopts from Linda Stone. Rheingold argues that students have too little control over where their devices lead their thoughts and suggests it is important to learn to manage attention (19). $\mathrm{He}$ is using classroom exercises to help his students focus their attention. He reports that most of his students recognize that they need this type of training and welcome it. In the long run, it might be better to use some of Rheingold's ideas, such as designating some portions of class as "technology on" and other times as "technology off." This might teach the lesson that there are times when technology is appropriate and some times when that is not true, especially if the instructor makes sure that students are using their phones constructively during the technology periods.

Warschauer has studied the results of using laptop computers in the classroom and found that this produced (a) more just-in-time learning; (b) more autonomous, individualized learning; (c) a greater ease of conducting research; (d) more empirical investigation; and (e) more in-depth learning (20). These seem to be desirable goals for any class. Although Warschauer's article was based on laptop use in middle and high school classes, it seems likely that a smart phone classroom would also display many of these characteristics.

The main difference between laptops and smart phones use would be that today's students tend to carry their smart phone with them everywhere, and so phones provide ubiquitous access. At this time, the main limitation is that not all students have smart phones; many have the less powerful feature phones. For the time being, it may be necessary to design cooperative exercises with small groups, at least one member of each group having a smartphone. As prices continue to fall for phone connections and more students have the more powerful phones, this should be less of a concern.

Several Chemistry faculty are beginning to experiment with the use of smart phones to teach Chemistry. Chemistry faculty at Abilene Christian University have been particularly active in using mobile devices because their school has issued iPhones or iPod Touches to all students. Professor Cynthia Powell did her doctoral research partially on the use of podcasts designed for smartphones for General Chemistry laboratory instruction (21) and is currently working with Professor Autumn Sutherlin, both presently from Abilene Christian University, to expand this type of podcast to courses in Biochemistry and General Science for pre-service teachers. Professor Lucille Benedict (University of Southern Maine) is having her students create short instructional videos for common laboratory instruments, and then use 2D barcodes to label instruments so that the video instructions can be accessed with a smartphone (22). Laura McDonald has used cell phones as an alternative to Personal Response Systems in her high school 
classroom (23). It seems clear that these are just the first steps into a new way to deliver instructional material.

The combination of the increasing popularity of ebooks and the willingness of people to read material on phones may make the smartphone more popular for delivery of instructional material. The increasing number of readers using the Kindle (24) or other similar devices, such as the iPad, will probably cause more people to turn to these devices to read their chemistry "texts". Ebooks are, however, not just texts but are already being released as rich, multimedia experiences. One recent example is "The Elements: A Visual Exploration" (25) offering access to videos, 3D images and stunning photography. While initially only available for the iPad, it has recently been made available for the iPhone (26). Even though the investment to deliver such texts and instructional material is significant, software tools will make their delivery easier with time and viewing on mobile phones may become as commonplace as dedicated ereaders.

\section{Conclusion}

It is clear that students with smart phones can access a virtual information commons that is equivalent to the holdings of a major research library. This is already changing how students learn, but what can be expected in the coming decade? The development of smart phone technology in the near future seems easy to predict. There is every indication that prices for both devices and connectivity will decrease, more and more students will have smart phones, and there will be an ever increasing number of applications that enhance the usefulness of the devices. It is more problematic to imagine what will be the future of smart phones in education. Perhaps the most important step is to stop thinking of these devices as phones; they are really powerful and portable computers. It is entirely possible that over the coming decade these devices may affect education in ways that match or exceed the personal computer revolution that has impacted education over the past two decades.

No technology is a panacea, and many of the traditional problems associated with educating students will remain, no matter how sophisticated the devices may become. Teachers still must be concerned with differences in motivation and ability, and the job of explaining difficult concepts will still represent a challenge. Perhaps the biggest test is that teachers will continually be challenged to be learners. This has always been the mark of a good teacher, but it is even more important when new technologies are constantly presenting new capabilities. The smart phone certainly represents an example of this type of development, but the further progress of mobile computing will continue to act as a stimulus and opportunity for innovative approaches to education. 


\section{Note}

A smart phone is generally described as a mobile phone that has a complete operating system available for application developers. Mobile phones that have less computing capability than a smart phone are called feature phones, although this distinction is not always agreed upon.

\section{Literature Cited}

1. 6/12: Cell Phone Nation. Marist Poll: Welcome to Pebbles and Pundits, http://maristpoll.marist.edu/612-cell-phone-nation/(Accessed Nov. 16, 2010).

2. Kolb, L. New Research on Students and Cell Phone Use. From Toy to Tool: Cell Phones in Learning (2010)., http://www.cellphonesinlearning.com/2010_03_01_archive.html (Accessed Nov 16, 2010).

3. Katz, J. E. Perpetual Contact: Mobile Communication, Private Talk, Public Performance; Cambridge University Press: Cambridge, UK, 2002.

4. Williams, A. J. "Mobile Chemistry-Chemistry in Your Hands and in Your Face." http://www.rsc.org/chemistryworld/Issues/2010/May/MobileChemistryChemistryHan dsFace.asp (Accessed Nov. 16, 2010).

5. http://www.rsc.org/chemistryworld/podcast/CWpodcast.asp (Accessed Dec 19, 2010).

6. http://www.nature.com/podcast/index.html (Accessed Dec 19, 2010).

7. http://itunes.apple.com/us/app/dilution/id348770086?mt=8 (Accessed Oct 15, 2010).

8. http://itunes.apple.com/app/the-chemical-touch/id288060442? $m t=8$ (Accessed Oct 15, 2010).

9. http://itunes.apple.com/us/app/chemjuice/id342895394?mt=8 (Accessed Oct 15, 2010).

10.

http://itunes.apple.com/WebObjects/MZStore.woa/wa/viewSoftware?id=284943090\&mt $=8$ (Accessed Oct 15, 2010).

11. http://itunes.apple.com/us/app/chemmobi/id320681328?mt=8 (Accessed Oct 15, 2010).

12. http://www.chemspider.com/blog/chemspider-mobile-goes-live.html (Accessed Dec 19, 2010).

13. Pence, H. E. and A. Williams (2010). "ChemSpider: An Online Chemical Information Resource." J.Chem.Ed. 87(11): 1123-4.

14. Young, J. (2010). "6 Top Smartphone Apps to Improve Teaching, Research, and Your Life." Chronicle of Higher Ed. Jan. 7, A11.

15. SN1 (2009). BB \& 2D barcodes. PH2.1 Occassional Brief Observations. 2010.(Accessed Dec. 8, 2010).

16. Pence, H. E. (2010). "Smartphones, Smart Objects, and Augmented Reality." The Reference Librarian, 52(1), 136-145.

17. Colakovic, A., B. Hewson, et al. (2010). Successful Sample Identification. B. Technology. April 1, 2010. http://www.biosciencetechnology.com/Application- 
Notes/2010/03/High-throughput-Instrumentation-Successful-Sample-IdentificationThermo-Fisher/ (Accessed Dec. 7, 2010).

18. Williams, A.J. (2000). Chemistry Databases in the Palm of Your Hand. http://www.scientificcomputing.com/chemistry-databases-in-the-palm.aspx (Accessed Dec 16, 2010).

19. Rheingold, H. (2009). Attention Literacy. Howard Rheingold: Online Investigator. 2010, http://www.sfgate.com/cgi-bin/blogs/rheingold/detail?entry_id=38828 (Accessed Dec. 8, 2010).

20. Warschauer, M. Information Literacy in the Laptop Classroom. Teachers College Record 2007, 109 (11), 2511-2540.

21. Powell, C. (2010). "Podcast effectiveness as scaffolding support for students enrolled in first-semester general chemistry laboratories." Doctoral Dissertation. University of North Texas, Denton, Texas.

22. Benedict, L. (2010). Tutorial on using a Spec 20 \#1. (2010). http://www.youtube.com/watch? v=GNPfssmPbWA (Accessed Dec. 5, 2010)

23. McDonald, L. M. (2010). "Anecdotal Uses of Facebook, Google Calendar, and Cell Phones in a High School Classroom." CCCE Newsletter. http://www.chedccce.org/confchem/instructions.html (Accessed Dec. 6, 2010).

24. http://www.amazon.com/dp/B002Y27P3M/?tag=googhydr20\&hvadid $=7616543259 \& r e f=p d \_s l \_b y 8 l f 4 t 35 \_$e (Accessed Dec 20, 2010).

25. http://itunes.apple.com/us/app/the-elements-a-visual-exploration/id364147847? mt=8 (Accessed Dec 6, 2010).

26. http://www.geardiary.com/2010/07/25/iphone-app-review-the-elements-by-theodoregray-adapted-for-the-iphone-4-by-touchpress/ (Accessed Dec 6, 2010). 

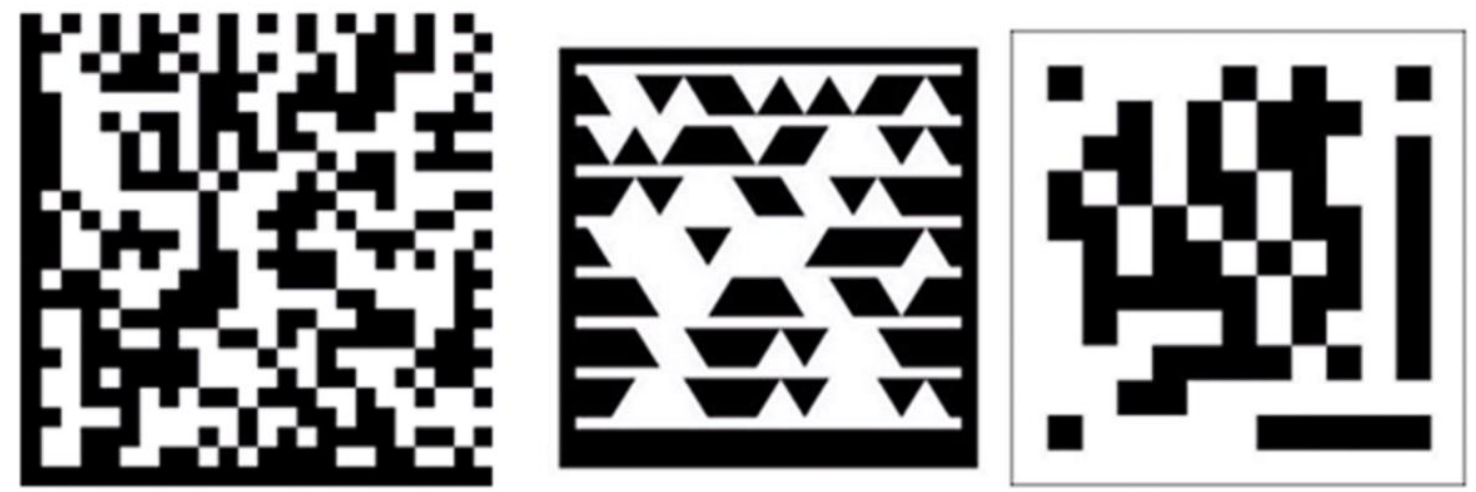

Figure 1: Some examples of two-dimensional barcode formats. Reading from left to right, "Quick Response" or QR code, Microsoft tag, and Scanlife code (12). 